considerations should be incorporated into disaster risk management planning.

Prehosp. Disaster Med. 2019;34(Suppl. 1):s73-s74

doi:10.1017/S1049023X19001596a

\section{Outbreak of Toxoplasmosis in the City of Santa Maria,} Brazil

Dr. Silvana Dal Ponte ${ }^{1}$, Ms. Daniela Burguez'2,

Mrs. Giordanna Andrioli ${ }^{1}$

1. Hospital De ClÃnicas De Porto Alegre-brazil, Porto Alegre, Brazil

2. Universidade Federal do rio Grande do Sul, Porto Alegre, Brazil

Introduction: In the first months of 2018, there was an increase in the number of cases of fever possibly related to toxoplasmosis in the city of Santa Maria, Brazil, reaching significant values. Toxoplasmosis is an autoimmune acute infection usually asymptomatic in $80-90 \%$ of immunocompetent adults. In this outbreak, the intensity of the symptoms presented warrants attention.

Objective: To report cases of the toxoplasmosis outbreak in the city of Santa Maria, Brazil.

Methods: This is a cross-sectional study using data on the outbreak of toxoplasmosis in Santa Maria published in bulletins by the Municipal Health Department of Santa Maria, Rio Grande do Sul, Brazil.

Results: The outbreak of toxoplasmosis in Santa Maria was confirmed on April 19, 2018. Until June 14, 2018, 510 cases were confirmed. According to the most recent bulletin released by the State Health Department on June 8, 2018, 441 occurrences are people residing in Santa Maria. Five are residents of the districts and seven cases are patients residing in neighboring counties. In a bulletin published on May 25, 2018, 1,116 cases were reported to state epidemiological surveillance by the end of May. Of these, 766 cases were still suspected (fever, headache and/or myalgia accompanied by lymphadenopathy, weakness, arthralgia, or change in vision. In the other 460 cases, there was laboratory confirmation of acute toxoplasmosis, of which 35 were pregnant, with two fetal deaths ( 36 and 28 weeks), and two abortions. There are also 212 cases still pending laboratory confirmation.

Discussion: The results of this research show that the current outbreak of toxoplasmosis in the city of Santa Maria, Brazil, is the largest reported in Brazil and appears to be the largest in the world. The notification to authorities by physicians was very important for the identification of this outbreak.

Prehosp. Disaster Med. 2019;34(Suppl. 1):s74

doi:10.1017/S1049023X19001602

\section{Pseudo Epidemic of Diarrhea Incidence: A Month Post Tsunami in Central Sulawesi, Indonesia Dr. Ajeng Tias Endarti ${ }^{1}$, Dr. Abdul Radjak ${ }^{1}$, Dr. Agus Handito ${ }^{2}$, Dr. Marlina Adisty, Prof. Sudarto Ronoatmodjo ${ }^{4}$ \\ 1. Mh Thamrin University, Kramat Jati, East Jakarta, Indonesia \\ 2. Sub-Directorate of Hepatitis and Gastrointestinal Infection, Ministry of Health, Central Jakarta, Indonesia \\ 3. National Disaster Management Board, Central Jakarta, Indonesia \\ 4. Faculty of Public Health, University of Indonesia, Depok, Indonesia}

Introduction: On Friday, September 28, 2018, the 7.4 Richter Scale earthquake hit Central Sulawesi and was followed by a tsunami. Within a month after the unpredictable earthquake and tsunami, a 773 aftershock earthquake was noted. These events took a major toll on the population in the affected areas. 2,086 people died and more than four thousand people were injured. 1.373 people went missing and 206.494 were evacuated. Surveillance data from November 4, 2018, to October 24,2018 , showed that an increased number of illnesses such as diarrhea was the second leading reported cases. Data showed that the number of diarrhea cases was 3.350 with two peaks of epidemic curves on October 10 and 22, 2018.

Aim: To verify the diarrhea outbreak after the tsunami in Palu, Donggala, and Sigi District.

Methods: Verification of medical records at six selected primary healthcare institutions with the highest number of cases of diarrhea.

Results: A pseudo-epidemic of diarrhea occurred. A high number of diarrhea cases occurred due to double reporting and misdiagnosed cases. Investigation reports showed that liquid defecation was considered diarrhea even though it occurred less than three times a day. The follow-up activity was contacting data entry managers to revise data, disseminate findings during the daily meeting of the health-related officers, and broadcasting findings through a WhatsApp group of provincial and district surveillance officers. Post-investigation, the number of diarrhea incidences was lower and the peak was not shown on the epidemic curve. It can be interpreted that a diarrhea outbreak did not occur in the tsunami-affected area in the Palu, Donggala, and Sigi districts.

Discussion: During a time of disaster, a chaotic situation led to improper data collection. Data verification should be conducted to assure the validity of reported data.

Prehosp. Disaster Med. 2019;34(Suppl. 1):s74

doi:10.1017/S1049023X19001614

Public Information, Education, and Communication (IEC) of Health: Active Participation of Health Practitioners in Urban Radio in a Low Resource Setting

Dr. Joseph Bonney ${ }^{1}$, Dr. Lawrence Osei-Tutu,

Dr. Richard Selormey ${ }^{2}$, Dr. Bernard Hammond,

Ms. Patricia Bonsu

1. Radiant MD, Kumasi, Ghana

2. Ultimate FM

3. Komfo Anokye Teaching Hospital

Introduction: Over the last two decades, Frequency Modulation (FM) radio has been established as the only form of sound broadcasting in Ghana. Radio is the most accessible of mass media. There are more than 40 operational radio stations in the Ashanti region of Ghana. Most stations are commercial, broadcasting in the local language (Asante-Twi). Many urban radio health slots discuss various diseases and their treatments mainly for the benefit of patients. Complementary and Alternative Medicine (CAM) practitioners who are able to pay for airtime dominate as 'experts' in most of these shows.

Methods: We identified an IEC gap regarding policies governing healthcare delivery, healthcare financing, training, ethics 